Research Article: New Research / Cognition and Behavior

\title{
Partial Ablation of Postsynaptic Dopamine D2 Receptors in the Central Nucleus of the Amygdala Increases Risk Avoidance in Exploratory Tasks
}

https://doi.org/10.1523/ENEURO.0528-21.2022

Cite as: eNeuro 2022; 10.1523/ENEURO.0528-21.2022

Received: 22 December 2021

Revised: 15 January 2022

Accepted: 4 February 2022

This Early Release article has been peer-reviewed and accepted, but has not been through the composition and copyediting processes. The final version may differ slightly in style or formatting and will contain links to any extended data.

Alerts: Sign up at www.eneuro.org/alerts to receive customized email alerts when the fully formatted version of this article is published.

Copyright @ 2022 Casey et al.

This is an open-access article distributed under the terms of the Creative Commons Attribution 4.0 International license, which permits unrestricted use, distribution and reproduction in any medium provided that the original work is properly attributed. 
1 Partial ablation of post-synaptic dopamine D2 receptors in the 2 central nucleus of the amygdala increases risk avoidance in exploratory tasks

4

5 Eric Casey ${ }^{1,4}$, María Elena Avale ${ }^{1,2}$, Alexxai Kravitz ${ }^{3,4,5}$, Marcelo Rubinstein ${ }^{1,2, *}$ 6

${ }^{1}$ Instituto de Investigaciones en Ingeniería Genética y Biología Molecular, Consejo Nacional de Investigaciones Científicas y Técnicas, 1428 Buenos Aires, Argentina;

${ }^{2}$ Departamento de Fisiología, Biología Molecular y Celular, Facultad de Ciencias Exactas y Naturales, Universidad de Buenos Aires, 1428 Buenos Aires, Argentina

${ }^{3}$ Department of Anesthesiology, Washington University St. Louis, St. Louis, Missouri 63108, USA

${ }^{4}$ Department of Psychiatry, Washington University St. Louis, St. Louis, Missouri 63108, USA

${ }^{5}$ Department of Neuroscience and Biomedical Engineering, Washington University St. Louis, St. Louis, Missouri 63108, USA

Author contributions: EC, MEA, AK and MR designed research; EC and MEA performed research; EC and MR analyzed data and wrote the paper; EC, MEA. AK and MR edited the paper.

* Corresponding author: Marcelo Rubinstein, INGEBI-CONICET, Vuelta de Obligado 2490, 1428-

Buenos Aires, Argentina Email: mrubins@dna.uba.ar

Abbreviated title: D2Rs in the CeA regulate risk avoidance (40 characters)

Number of figures: 7 Tables: 0

Abstract: 201 words, Introduction: 387 words, Discussion: 855 words

Conflicts of interest: The authors declare no conflict of interest.

Acknowledgments: This work was supported by grants from the Agencia Nacional de Promoción Científica y Tecnológica, Argentina (MR) and a doctoral fellowship from CONICET, Argentina (EC). The authors declare no conflicts of interest. 
26

27

28

\section{Abstract}

The central nucleus of the amygdala ( $\mathrm{CeA})$ is involved in the expression of fear and has been implicated in several anxiety disorders. This structure is densely innervated by dopaminergic projections that impinge on amygdalar neurons expressing various dopamine receptor subtypes, including D2 receptors (D2Rs). Although various pharmacological approaches have assessed the role of D2Rs in the CeA, the actual participation of post-synaptic D2Rs in the CeA to defensive behaviors remains unclear. Here, we investigated the distribution of D2Rs in the $\mathrm{CeA}$ and their role in modifying neuronal activity and fear related behaviors in mice. First, using the mouse reporter strain D2R-EGFP, we verified that D2Rs are present both in neurons of the CeA and in A10dc DAergic neurons that innervate the CeA. Moreover, we showed that pharmacological stimulation of D2Rs increases the activity of PKC $\delta$ cells present in the CeA, a type of neuron previously associated with reduced defensive behaviors. Finally, using a molecular genetics approach that discriminates postsynaptic D2Rs from presynaptic D2 autoreceptors, we demonstrated that mice carrying targeted deletions of postsynaptic D2Rs in the CeA display increased risk avoidance in exploratory tasks. Together, our results indicate that postsynaptic D2Rs in the CeA attenuate behavioral reactions to potential environmental threats. 
D2Rs in the CeA regulate risk avoidance - Casey et al., 2021

\section{Significance Statement}

46 The central nucleus of the amygdala $(\mathrm{CeA})$ is a neural hub involved in risk assessment and fear-

47 related behaviors, and its malfunction may trigger anxiety disorders. The CeA is densely

48 innervated by dopamine projections that activate D1 and D2 receptors (D2R). In this study we

49 sought to determine the role that postsynaptic D2Rs in the CeA exert in defensive behaviors.

50 We first showed that pharmacological stimulation of D2Rs increases the activity of neurons

51 known to reduce defensive behaviors. We also showed that mice partially lacking postsynaptic

D2Rs in the CeA display increased risk avoidance in exploratory tasks. Together, our results indicate that $\mathrm{D} 2 \mathrm{Rs}$ in the $\mathrm{CeA}$ attenuate behavioral reactions to potentially aversive environmental stimuli rising new perspectives to manage anxiety disorders. 
D2Rs in the CeA regulate risk avoidance - Casey et al., 2021

\section{Introduction}

Risk assessment, fear, and threat avoidance are highly conserved adaptive behaviors that are essential for fitness and survival. In some cases, however, fear responses appear as exaggerated behavioral reactions to stimuli that do not represent a commensurate threat, underling symptoms of pathological conditions such as anxiety and post-traumatic disorders. Uncontrollable anxiety may also lead to compulsive behaviors commonly observed during withdrawal from major abused drugs such as opioids, cocaine, nicotine, and ethanol (Koob, 2008).

The central nucleus of the amygdala $(\mathrm{CeA})$ is a neural hub that orchestrates innate and learned fear-related behaviors. The CeA is densely innervated by dopaminergic fibers arriving mainly from A10 dorsocaudal (A10dc) neurons located in the ventral periaqueductal gray (vPAG) and dorsal raphe (DR) (Hasue and Shammah-Lagnado, 2002; Li et al., 2016). The dopamine (DA) D2 receptor gene (DRD2) is expressed in the CeA of rodents (Scibilia et al., 1992; Kim et al., 2017; McCullough et al., 2018a, 2018b) and humans (Gurevich et al., 1999; Xiang et al., 2008). In mice, DA D2 receptors (D2Rs) present in the CeA have been implicated in impulsive behaviors (Kim et al,, 2018) whereas several association human studies have linked particular genetic polymorphisms of DRD2 with avoidance behavior (Frank and Hutchison, 2009), social phobia (Schneier et al., 2000), social dysfunction (Lawford et al., 2006) and anxiety-driven alcoholism (Joe et al., 2008). Given the involvement of the CeA in defensive behaviors, and its regulation by DA, we hypothesized that D2Rs in the CeA regulate behavioral responses to potential threats, and that ablation of postsynaptic D2Rs in the mouse CeA would increase avoidance behaviors. Although previous studies have used local applications of antagonists to evaluate the function 
of D2Rs in the CeA (Guarraci et al., 2000; De la Mora et al., 2012; De Bundel et al., 2016), pharmacological approaches are unable to discriminate between the blockade of pre- and postsynaptic D2Rs.

In this study, we sought to investigate the role of amygdalar D2Rs in defensive and fear related behaviors. To this end, we first evaluated the distribution of post- and presynaptic D2Rs in the CeA. Then, we determined the pattern of CeA neurons activated by pharmacological stimulation of D2Rs. Finally, we used a molecular genetics approach to partially eliminate postsynaptic D2Rs from the $\mathrm{CeA}$ and studied their risk assessment behaviors in approach/avoidance conflict paradigms. Altogether, our results support the hypothesis that postsynaptic D2Rs in the CeA play an active role in threat assessment of environmental cues.

\section{Materials and Methods}

\section{Mice husbandry}

Mice of both sexes were housed in ventilated cages under controlled temperature and photoperiod (12-h light/12-h dark cycle, lights on from 7:00 AM to 7:00 PM), with tap water and laboratory chow available ad libitum, and separated by sex. For behavioral experiments and drug administration 7-16 week-old mice were transferred to an experimental animal room with similar housing conditions and allowed for at least 1 week of habituation prior to experiments. All procedures followed the Guide for the Care and Use of Laboratory Animals, United States Public Health Services (2011) and in agreement with the INGEBI-CONICET Institutional Animal Care and Use Committee. $\operatorname{Drd} 2^{-\%}$ and $\operatorname{Drd} 2^{\operatorname{loxP} / / 10 \times P}$ mice were generated by crossing a heterozygote male mouse carrying the original floxed exon 2- floxed PGK-neo Drd2 
allele with a B6.FVB-Tg(Ella-cre)C5379Lmgd/J female (Jackson Laboratory, USA) and then backcrossed for more than 10 generations to $\mathrm{C} 57 \mathrm{BL} / 6 \mathrm{~J}$, as previously described in detail (Bello et al., 2011). $\operatorname{Drd} 2^{10 \times P / 10 \times P}$ mice are conditional mutants carrying targeted loxP sites flanking $D r d 2$ exon $2\left(\operatorname{Drd2} 2^{\text {tm1.1Mrub } / J) . ~ D r d 2} 2^{\text {loxP/loxP }}, \operatorname{Drd2}^{-\%}, \operatorname{Dat}^{+/ 1 R E S-C r e}\right.$ (Bäckman et al., 2006), Drd2-EGFP (Gong et al., 2003) and Ai14 (Madisen et al., 2010) mice were all bred in our facility and maintained in a C57BL/6J background.

\section{Stereotaxic surgeries}

Mice were anesthetized with ketamine (100 mg/kg; i.p.) and xylazine hydrochloride $(10 \mathrm{mg} / \mathrm{kg}$; i.p.). A $10 \mu \mathrm{l}$ Hamilton syringe connected with a 36-gauge metal needle was used to infuse lentiviral vectors using a microsyringe pump at $0.1 \mu \mathrm{l} / \mathrm{min}$. Stereotaxic coordinates for the $\mathrm{CeA}$ were in relation to the Bregma (Paxinos and Franklin, 2008): anterior-posterior, $-1.5 \mathrm{~mm}$; medial-lateral, $+/-3.0 \mathrm{~mm}$; dorsal-ventral, $-4.9 \mathrm{~mm}$. Following infusion, the needle was kept at the injection site for $5 \mathrm{~min}$, and then slowly withdrawn to half way, kept there for 2 more min and then slowly withdrawn outside the brain. Skin was sutured, local anesthesia (lidocaine gel) was applied followed by the analgesic flunixin meglumine ( $5 \mathrm{mg} / \mathrm{kg}$, s.c.). Mice were maintained on a regulated warm pad and monitored until recovery from anesthesia.

Mice received $0.6 \mu \mathrm{l}$ of a solution containing $3.3 \times 10^{8}$ particles $/ \mathrm{ml}$ directly into the CeA, bilaterally. CeADrd2KO mice were generated by stereotaxic co-injections of LV:GAD-Cre $\left(1.65 \times 10^{8}\right.$ viral particles/ml) and LV:Ub-EGFP $\left(1.65 \times 10^{8}\right.$ viral particles/ml) into the CeA of $\operatorname{Drd} 2^{\text {IoxP/loxP }}$ mice whereas control mice received injections of LV:Ub-EGFP $\left(3.3 \times 10^{8}\right.$ particles $\left./ \mathrm{ml}\right)$ alone. The same procedure was performed for LV:GAD-Cre and LV:Ub-EGFP injections in wildtype mice $\left(\operatorname{Drd} 2^{+/+}\right)$for control experiments. 


\section{Lentiviral preparations}

HEK-293Tcells were grown on high glucose DMEM (Invitrogen), supplemented with 10\% (v/v) fetal bovine serum (Natocor, Argentina), $0.5 \mathrm{mM}$ L-glutamine, $100 \mathrm{U} / \mathrm{ml}$ penicillin and 100 $\mu \mathrm{g} / \mathrm{ml}$ streptomycin. Cells at $80-85 \%$ confluence in $100 \mathrm{~mm}$ plates were co-transfected with 3 $\mu \mathrm{g}$ of the lentiviral shuttle vector (either GAD-CRE or Ub-EGFP) together with helper vectors encoding packaging and envelope proteins (CMV $\Delta 8.9$ and CMV-VSVg, 3 and $1.5 \mu \mathrm{g}$ respectively), using lipofectamine (Plus reagent, Thermo Fisher). Viral particles were harvested from the culture medium $36 \mathrm{~h}$ after transfection, treated with RNase-free DNase I (Invitrogen), filtered and concentrated by ultracentrifugation at 100,000 x g (Ti 90 rotor, Beckman), yielding viral suspensions at a titer of $10^{7} \mathrm{TU} / \mathrm{ml}$. LV aliquots were stored at $-80^{\circ} \mathrm{C}$ and thawed on ice before use. LV:GAD-Cre carries Cre recombinase coding sequences driven by the mouse GAD67 promoter whereas LV:Ub-EGFP carries EGFP coding sequences driven by the human ubiquitin promoter. Both viral vectors contain a woodchuck hepatitis virus post-transcriptional regulatory element (WPRE); long terminal repeats (LTR); RNA pack and genomic RNA packaging signals; a rev response element (RRE), a central polypurine tract (cPPT), a central termination sequence (CTS), a 3'end polypurine tract (3-PPT) and a $\Delta$ U3 400-bp deletion in the 3' LTR.

\section{Tissue collection and histology}

Transcardiac perfusions were performed with phosphate buffered saline (PBS, 0.9\% $\mathrm{NaCl}, 2.7$ $\mathrm{mM} \mathrm{KCl}, 10 \mathrm{mM} \mathrm{K}_{2} \mathrm{HPO}_{4}, 2 \mathrm{mM} \mathrm{KH} \mathrm{PO}_{4}, \mathrm{pH}$ 7.5) followed by paraformaldehyde $4 \%$ in PBS and brains were removed and post-fixed in the same solution at $4^{\circ} \mathrm{C}$ for $12-16 \mathrm{~h}$. Brains were sectioned at $40 \mu \mathrm{m}$ on a vibratome (Leica) and used immediately or stored at $-20^{\circ} \mathrm{C}$ in a solution containing $30 \%(\mathrm{v} / \mathrm{v})$ ethylene glycol, $30 \%(\mathrm{v} / \mathrm{v})$ glycerol and PBS, until they were processed for immunofluorescence. Immunolabeling was performed as follows: free-floating sections were 
rinsed three times for $10 \mathrm{~min}$ in PBS. For PKC $\delta$ immunofluorescence an antigen-retrieval protocol was applied: following PBS rinse, sections were incubated in citrate buffer (10mM citric acid, $0.05 \%$ Tween-20, $\mathrm{pH}=6.0$ ) at $95^{\circ} \mathrm{C}$ for $5 \mathrm{~min}$ and then rinsed three times for $10 \mathrm{~min}$ in PBS. Sections were incubated for $16 \mathrm{~h}$ at $4^{\circ} \mathrm{C}$ in primary antibody solution with normal goat serum $2 \%(\mathrm{w} / \mathrm{v}), 0.3 \%$ Triton $\mathrm{X}-100$, in PBS. The following primary antibodies were used: rabbit anti-TH (1:2,000; Millipore, AB5935), chicken anti-TH (1:1,000; Abcam, AB76442), rabbit anti-CFOS (1:500, Santa Cruz Biotechnology, SC-52), mouse anti-PKC $\delta$ (1:500, BD Biosciences, 610398), chicken anti-EGFP (1:1,000; Aves, GFP-1020). After incubation with a primary antibody, sections were rinsed twice for $20 \mathrm{~min}$ in PBS and then incubated for $2 \mathrm{~h}$ at room temperature with goat or donkey Alexa-488 or Alexa 555 coupled secondary antibody 1:1,000 in $0.3 \%$ Triton X-100 in PBS. Finally, sections were rinsed twice for 20 min in PBS and mounted with Vectashield (Vector Labs) for confocal microscopy or glycerol $50 \%(\mathrm{v} / \mathrm{v}$ ) in PBS for fluorescence and bright field microscopy.

\section{Microscopy and images analysis}

Confocal images for co-expression assays and quantification were obtained using a Leica Confocal TCS-SPE microscope. Images not used for colocalization analysis were obtained by fluorescence microscopy. Images were analyzed with the Fiji platform (Schindelin et al., 2012) of the ImageJ software (Rueden et al., 2017). For c-FOS quantification, cell number was semiautomatically quantified with the tool "Analyze particles" after manually delimitating the region of interest. Colocalization images were obtained by confocal microscopy and was manually quantified using the tool "Cell Counter".

\section{Experimental design and statistical analyses}




\section{Drug administration and c-FOS detection}

Mice of both sexes older than 8 weeks were used. All drugs were dissolved in $\mathrm{NaCl} 0.9 \%$ to reach a concentration such that the injected volume was $0.1 \mathrm{ml}$ per $10 \mathrm{~g}$ of body weight. Experiments evaluating cocaine and quinpirole effects were performed separately, and because of that, they were not analyzed in the same statistical analysis. Vehicle ( $\mathrm{NaCl} 0.9 \%)$, cocaine hydrochloride (20 mg/kg; Sigma) or quinpirole (1 mg/kg; Sigma) were injected i.p.. This dose of quinpirole was selected based on a previous report showing increased expression of the neuronal activation marker P-rpS6 in CeA neurons (De Bundel et al., 2016). Mice were left in their home cages and 90 min later were perfused for tissue fixation and histology.

The number of c-FOS immunostained cells per hemisphere and coronal section (between 2 and 5 per mouse) was obtained. For plotting, the average number of cells between hemispheres and sections of the same mouse was calculated. For statistical analysis, sections corresponding to the same mouse were treated as sub-samples of the same mouse. Colocalization of c-FOS and PKCס (Fig. 2B-C) was analyzed with a two-ways generalized linear mixed model with Poisson distribution (Fig. 2B) or Negative Binomial distribution (Fig. 2C), with Drug as betweensubjects factor with 2 levels (vehicle and quinpirole, or vehicle and cocaine), Neuronal population as intra-subjects factor with 2 levels (PKC $\delta+$ and PKC $\delta-)$, Mouse as random variable and Section-hemisphere as sub-samples (Neuronal population nestled in Mouse, and Sectionhemisphere nestled in Neuronal population/Mouse). c-FOS in wild-type vs Drd2KO mice was analyzed with a two-ways generalized linear mixed model with Negative binomial distribution, with Drug as between-subjects factor with 2 levels (vehicle and quinpirole), Genotype as between-subjects factor with 2 levels (wild-type and Drd2KO), Mouse as random variable and 
Section-hemisphere as sub-samples (nestled in Mouse). Significance was evaluated with the likelihood-ratio test (LTR). Post-hoc Tuckey multiple comparisons were performed.

\section{Behavioral tests}

$\operatorname{Drd} 2^{\text {IoxP/loxP }}$ male mice older than 8 weeks were injected with a combination of LV:GAD-Cre and LV:Ub-EGFP (CeADrd2KO group) or LV:Ub-EGFP alone (control group), and after 2-3 weeks were evaluated in a battery of tests to evaluate avoidance behaviors (open field (OF), dark-light box test (DLBT) and elevated plus maze (EPM)) and fear conditioning (FC). As a control experiment, wild-type male mice older than 8 weeks received identical surgeries and behavioral tests except for the fear conditioning (LV:GAD-Cre group and LV:Ub-EGFP group). Two littermate cohorts were used to reach sample size per group (CeADrd2KO=9, Ctrl= 8; GAD-Cre= 7, Ub-EGFP= 7).

Differences in avoidance behavior were evaluated with a Multivariate Analysis of the Variance (MANOVA) including the values obtained from the OF (time in center), the DLBT (time in light, latency to first enter to light and number of entries to light) and the EPM (percentage of time on open arms or normalized time on open arms (see the "Elevated plus maze" section), and entries to open arms). In addition, the results of the MANOVA were confirmed with individual univariate tests (described in the section of each test).

Open field exploration test. Horizontal locomotion and exploration in a novel open field were evaluated in activity boxes (Med Associates) for $30 \mathrm{~min}$ for 3 consecutive days. Total distance travelled during the first 5 min of the each day, and the time in the center of the arena, were determined using the software Activity Monitor (Med Associates). Time in center was evaluated 
by t-test. Distance was evaluated in a 2-ways ANOVA with repeated measures, with group as between-subjects factor and day as intra-subject factor with 3 levels (day 1, day 2 and day 3).

Elevated plus maze. We used a custom-made apparatus standing $50 \mathrm{~cm}$ above the floor and constructed with black acrylic. Each arm of the maze is $5 \mathrm{~cm}$ wide and $30 \mathrm{~cm}$ long. The closed arms have black acrylic walls, $12 \mathrm{~cm}$ high. Mice were individually placed in the center of the maze and allowed to explore for 5 min while being videotaped. Entry to an arm was counted when more than half of the body of the mouse was inside the arm. Percentage of time on open arms was calculated with the formula: $100 \times$ time on open / (time on open + time on closed); percentage of entries to open was calculated with the formula: $100 \mathrm{x}$ entries to open/(entries to open + entries to closed). Univariate differences in percentage of time spent on the open arms were evaluated with a t-test; univariate differences in percentage of entries to open arms were evaluated with Wald's test in a generalized linear model with quasi-binomial distribution. Only for the percentage of time spent on the open arms in $\operatorname{Drd} 2^{\text {loxP/loxp }}$ mice, significant effect of the cohort was detected. In addition, the variance also differed between cohorts, causing a non-normal distribution of the residuals. Therefore, the data was analyzed in two different ways: first, using a 2-ways ANOVA with group and cohort as between-subjects' factors with variance modeling (Varldent function, library "nlme"); second, dividing each value by the average of its respective cohort (independently of the group) and analyzing this normalized data with a t-test. Since the normalization restored the normal distribution of the residuals, normalized data was used for the MANOVA of $\operatorname{Drd} 2^{\text {loxP/loxP }}$ mice instead of the original percentage of time spent on the open arms. 
Light/dark box test. A custom-made two-chamber shuttle box containing a dividing wall with a $4 \times 5-\mathrm{cm}$ hole in the center that allows mice free access to both sides was used. Each chamber is $20(\mathrm{w}) \times 26(\mathrm{I}) \times 14 \mathrm{~cm}(\mathrm{~h})$ with steel walls and floor. Mice were placed on one side of the shuttle box that was then immediately covered with a black acrylic ceiling. The other chamber received ambient illumination. Mice were allowed to explore the chambers for 5 min while videotaped. The time prior to entering into the lit compartment (latency), the time spent on the illuminated side, and the number of entries to the lit compartment were determined. Entry to or exit from the lit compartment was counted when the mouse passed more than half of its body. Univariate differences in latency and time spent on the illuminated chamber were evaluated by t-test. Univariate differences in number of entries were evaluated with Wald's test in a generalized linear model with Poisson ( $D r d 2^{\text {loxP/loxP }}$ mice) or quasi-Poisson (wild-type mice) distribution.

Fear conditioning. The conditioning chamber consisted in an operant chamber 14.0 (w) x 15.9 (l) $x 12.7$ (h) cm (Med Associates) with steel rods on the floor connected to a scrambler (Med Associates), placed inside a closed ventilated box for sensorial isolation. Mice were introduced into the chamber and light was turned on. After 2 min habituation, 3 consecutive shocks $(0.35$ $\mathrm{mA}, 2 \mathrm{sec}$ duration) were applied with an inter-trial interval of $90 \mathrm{~s}$. One min after the third shock, light turned off and mice were removed and returned to their home cages. $24 \mathrm{~h}$ later mice were reintroduced into the chamber for 5 min to test contextual conditioned freezing. Mice were videotaped during the entire training and testing sessions. Freezing behavior was hand scored by videotape observation and freezing or active avoidance were determined in continuous $4 \mathrm{~s}$ bins. Freezing behavior was presented as the percentage of freezing events over 
total events. Differences in the percentage of time freezing behavior in each stage of the training (baseline, after first shock, after second shock and after third shock) and the testing were evaluated by MANOVA and further validated by univariate tests. Univariate differences in the percentage of time freezing were evaluated by Wald's test in a generalized linear model with quasi-binomial distribution for baseline and test stages, and by likelihood-ratio test in a generalized linear mixed model with quasi-binomial distribution with the Group as between subjects' factor and Shock as within-subject factor with three levels (shock 1, shock 2 and shock 3) in the case of the post shocks part of the training.

\section{Software and statistics}

All data represent the mean \pm SEM and were graphed using GraphPad Prism Software (Version 5.01, 2007 GraphPad Software inc., San Diego, USA) and analyzed using R Studio (Version 3.2.3). Data with continuous variables were analyzed by Student's $t$ test, ANOVA or repeated measures ANOVA. Normal distribution and homoscedasticity were verified with Shapiro test, QQ-plot and Levene test (library "car"). When appropriate, variance was modeled with Varldent function (library "nlme"). Discrete data were analyzed with generalized linear models (GLM) or generalized linear mixed model (GLMM) with Poisson error structure (link:loggit). Variables corresponding to rates of success over total trials were analyzed using GLM with Binomial error structure (link:log). For GLM and GLMM, significances were evaluated with "likelihood-ratio test" comparing nestled models, or Wald test in the case of Quasi-binomial models. Assumptions were evaluated assessing the absence of patterns in Pearson's residuals graph and calculating the dispersion parameter to assess subdispersion or overdispersion. When assumptions were not achieved, Negative-binomial or quasi-Poisson distributions instead 
Poisson, or Quasi-binomial instead Binomial, were used. For multivariate analysis of variance, univariate and multivariate normality (Royston's test, library "MVN") and homogeneity of covariance matrices (Box test, library "biotools") and absence of multivariate outliers (Mahalanobis distance) were verified.

\section{Code Accessibility}

Data analysis and tables can be accessed at https://github.com/casey-e/Casey-et-al-2021

\section{Results}

\section{Pre- and post-synaptic distribution of D2R in the CeA}

To identify neurons expressing D2Rs in the CeA, we performed a comprehensive histological analysis of coronal brain slices of Drd2-EGFP BAC transgenic mice (Gong et al., 2003). In agreement with previous reports using in situ hybridization (Kim et al., 2017; McCullough et al., 2018a), we found a wide distribution of neuronal cell bodies expressing D2Rs along the lateral division of the $\mathrm{CeA}(\mathrm{CeL})$ and through the entire antero-posterior axis of this division (Fig. 1A). In contrast, D2R-positive cell bodies were only sparsely detected in the medial division (CeM), and mainly located near the boundaries of the CeL (Fig. 1A). To analyze if D2R expressing neurons are innervated by DAergic terminals we crossed Drd2-EGFP mice with mutant mice carrying a Dat ${ }^{I R E S-C r e}$ knockin allele (Bäckman et al., 2006) and the Cre-inducible tdTomato reporter gene Ai14 (Madisen et al., 2010) that, together, label DAergic neurons with red fluorescence. Using these triple transgenic mice, we found that D2R expressing neurons and DAergic fibers largely overlap in the CeL (Fig. 1B), suggesting that D2Rs of the CeA are 
functional receptors regulated by DA. In addition, we detected a low density of DAergic fibers in the CeM, a CeA division with sparse D2R expressing neurons (Fig. 1B).

Then, we investigated whether the major DAergic input to the CeA, originating from the vPAG/DR (Hasue and Shammah-Lagnado, 2002; Li et al., 2016), expresses D2Rs that may function as D2 autoreceptors in the CeA. Using Drd2-EGFP mice we found that most DAergic vPAG/DR neurons also express the reporter transgene driven by $\operatorname{Drd} 2(81.8 \pm 9.7 \%$ of total THimmunoreactive neurons) (Fig. 1C-D), a result that supports prior data suggesting D2 autoreceptor regulation of DA release in the CeA (Bull et al., 1991). Together, these data indicate that $\mathrm{D} 2 \mathrm{Rs}$ in the CeA are present both post and pre-synaptically.

\section{D2Rs stimulate PKC $\delta+$ neurons in the $\mathrm{CeA}$}

The neuronal circuits of the CeA involved in the processing of fear-induced behaviors have been described in detail (Ciocchi et al., 2010; Janak and Tye, 2015; Kim et al., 2017). A group of CeL neurons expressing the molecular marker protein kinase $C \delta(\mathrm{PKC} \delta+)$ is known to reduce the expression of defensive behaviors by inhibiting projection neurons of the CeM (Ciocchi et al., 2010; Haubensak et al., 2010; Tye et al., 2011). Conversely, PKCס- neurons of the CeL facilitate the expression of fear responses by inhibiting PKC $\delta+$ CeL neurons (Ciocchi et al., 2010; Haubensak et al., 2010). To study the participation of D2Rs in the CeA, we investigated whether PKC + and PKC $\delta$ - neurons are differentially activated by D2R stimulation using an immunofluorescence coexpression analysis of PKC $\delta$ and the immediate early gene $c$-Fos. We found that both the DA transporter blocker cocaine $(20 \mathrm{mg} / \mathrm{kg}$, i.p.) and the $\mathrm{D} 2 \mathrm{R}$ agonist quinpirole $(1 \mathrm{mg} / \mathrm{kg}$; i.p.) increased the number of c-FOS+ nuclei in the CeL. Furthermore, the 
increase in c-FOS expression was significantly greater in PKC $\delta+$ neurons than in PKC $\delta$ - neurons (likelihood-ratio test for the interaction between drug and cell type), being 3-fold greater in cocaine injected mice (Fig. 2A, B) and 6-fold greater in quinpirole injected mice (Fig. 2A, C), in agreement with a previous report (De Bundel et al., 2016). The effect of quinpirole was mediated exclusively by D2Rs, since the number of c-FOS+ nuclei was not increased when given to $\operatorname{Drd}^{-/}$(knockout) mice (Fig. 2D-E). These results indicate that stimulation of D2Rs activate PKC $\delta+$ neurons in the CeA. Because PKC $\delta+$ neurons in the CeA have been shown to mediate anxiolytic effects (Haubensak et al., 2010; Cai et al., 2014), we hypothesized that D2Rs present in this region regulate risk assessment.

\section{Ablation of postsynaptic D2Rs in the CeA increases avoidance in exploratory tasks}

To investigate the participation of amygdalar D2Rs in behavioral reactions involved in risk assessment we generated mice partially lacking postsynaptic D2Rs in the CeA and tested them in several approach/avoidance conflict paradigms. The molecular strategy used to specifically ablate postsynaptic D2Rs without affecting D2 autoreceptors was based on the expression of Cre recombinase directly into the CeA of $\operatorname{Drd} 2^{\text {loxp/loxP }}$ mice, a homozygous strain carrying conditional Drd2 null alleles (Bello et al., 2011). To this end, we used a lentiviral vector expressing the Cre recombinase under the control of the GAD67 promoter (Tolu et al., 2010) (LV:GAD-Cre; Fig. 3A top) together with a lentiviral vector expressing EGFP under the control of the human ubiquitin promoter that allows later visualization of the injection site (LV:Ub-EGFP; Fig. 3A bottom). The use of the GAD67 promoter to drive Cre was based on the fact that CeA neurons are GABAergic (McDonald, 1982; Ehrlich et al., 2009). We performed bilateral 
stereotaxic co-injections of LV:GAD-Cre and LV:Ub-EGFP into the CeA of Drd2 $2^{\text {loxP//oxp }}$ mice (from now on, CeADrd2KO mice) (Fig 3B), to excise the essential exon 2 of $\operatorname{Drd2}$ (Fig. 3C). Control $\operatorname{Drd} 2^{\text {IoxP/loxP }}$ mice received LV:Ub-EGFP injections only (Fig. 3C). Two to three weeks after this procedure, mice were subjected to a battery of approach/avoidance conflict paradigms where their behaviors were evaluated (Fig. 3D). At the conclusion of these tests, the injection sites were determined histologically for each mouse (Fig. 3E). Cre-induced deletion of exon 2 from the floxed Drd2 alleles was verified by PCR using DNA extracted from the CeA (Fig. 3F). In addition, to validate the efficacy of the viral vectors to target CeA neurons expressing D2Rs, we injected LV:GAD-Cre into the CeA of compound Drd2-EGFP.Ai14 transgenic mice and confirmed that the injections were limited to the CeA inducing tdTomato expression in $38 \pm 14 \%$ (average \pm confidence interval, $\mathrm{n}=5$ injections) of Drd2-EGFP+ neurons at the injection site (Fig. 3G). Noteworthy, we did not detect tdTomato+ neurons in any of the input areas projecting to the CeA, demonstrating that transduction of the LV was restricted to postsynaptic neurons and was not retrogradely transported.

A multivariate analysis of variance (MANOVA) for measures of approach/avoidance conflicts demonstrated that CeADrd2KO mice are significantly different from control mice (1 way MANOVA, Pillai $=0.7$, approx. $F(1,15)=3.9, p=0.03$, Fig. 4). In agreement, using univariate analysis we found that CeADrd2KO mice spent significantly less time than control mice in the lit compartment of the dark/light box (Fig. 4A, left), showed greater latencies to enter for the first time into this compartment (Fig. 4A, middle), and entered fewer times into the lit box (marginal difference ( $p=0.09$ ), Fig. $4 A$, right). Similarly, CeADrd2KO mice spent significantly less time on the open arms of the elevated plus maze than their control siblings (Fig. 4B, top-left and right), and the percentage of entries into the open arms over the total number of arm entries followed 
the same trend (Fig. 4B, bottom-left and right). Differently, the time spent in the center of the open field was similar in CeADrd2KO and control mice (Fig. 4C).

The increased avoidance behaviors observed in CeADrd2KO mice cannot be attributed to lower motivation for exploring new environments or to lower locomotor activity, because LV:GAD-Cre injections did not affect the distance travelled in the open field during the first day (when the arena is a novel environment) or in the second or third days (when the arena is a known environment) (Fig. 5).

To verify that the increased avoidance behaviors described in Fig. 4 were caused by the selective elimination of postsynaptic D2Rs from the CeA, we administered LV:GAD-Cre and LV:Ub-EGFP directly into the CeA of $\mathrm{Drd2}^{+/+}$mice (wild-type mice without loxP sites flanking exon 2, Fig. 6A) and challenged them with the same battery of behavioral tests (Fig. 6B). Drd2 $2^{+/+}$ mice receiving $L V: G A D-C r e$ injections did not show any behavioral difference in these tests compared to mice receiving LV:Ub-EGFP only ( 1 way MANOVA, Pillai= 0.5 , approx. $F(1,12)=$ 1.0, $\mathrm{p}=0.48$, Fig. $6 \mathrm{C}-\mathrm{E})$, indicating that the enhanced avoidance displayed by CeADrd2KO mice was in fact due to the elimination of postsynaptic D2Rs from the CeA. Finally, CeADrd2KO mice did not differ from control mice in the time spent freezing when re-exposed to a chamber previously associated to unavoidable foot-shocks ( 1 way MANOVA, Pillai= 0.2 , approx. $F(1,15)=$ $0.6, p=0.67$, Fig. 7A-D). Together, these results indicate that partial ablation of postsynaptic D2R in the CeA increases avoidance in exploratory tasks and suggest that amygdalar D2Rs control behavioral responses to riskier environments. 


\section{Discussion}

In this study, we used a conditional site-specific genetic approach in mice and found that partial ablation of postsynaptic D2Rs in the CeA increased avoidance behaviors in approach/avoidance conflict paradigms, suggesting that DA stimulation of amygdalar D2Rs regulates behavioral reactions to potential threats present in novel environments. The enhanced avoidance behavior observed in mice partially lacking D2Rs in the CeA was more profound when mice were studied in the dark-light box test than in the elevated plus maze. This milder, although significant, effect was likely caused by a strong and significant Cohort effect in the time spent on the open arms of the elevated plus maze, probably driven by variable and undetermined environmental conditions existing at the different moments when the two mouse cohorts were studied. Noteworthy, a two-ways ANOVA indicated significant main effects of the Group and the Cohort, indicating that the effect of D2R ablation in the CeA had similar effects in both cohorts.

Although D2Rs in the CeA have been previously studied using pharmacological compounds (Guarraci et al., 2000; De la Mora et al., 2012; De Bundel et al., 2016), we believe this is the first report investigating the effects on defensive behaviors elicited by the genetic ablation of postsynaptic D2Rs directly into the CeA. Although the lentiviral-mediated approach used in this study induced only a partial ablation of D2Rs in the injected CeA (Fig. 3G), this limited deletion showed to be enough to alter the behavioral reactions of potentially dangerous environments (Fig. 4), without affecting spontaneous locomotor activity (Fig. 5) or fear memory (Fig. 7). In contrast, previous studies based on local applications of D2R antagonists into the CeA had shown no changes in risk avoidance behavior, although elicited impaired reactions to fear conditioning (Guarraci et al., 2000) and unconditioned fear (De la Mora et al., 2012). Such 
differences may be due to the fact that pharmacological agents not only act on postsynaptic D2Rs but also on D2 autoreceptors that control DA release (Bello et al., 2011). Indeed, using Drd2-EGFP mice we found that most TH immunoreactive neurons present in the VPAG/DR also express Drd2 (Fig. 1C-D), a result supported by data collected in the Allen Mouse Brain Atlas showing intense labeling of Drd2 mRNA in vPAG/DR cell bodies (Lein et al., 2007). Furthermore, the D2R antagonist sulpiride has been shown to potentiate DA release elicited by optogenetic activation of vPAG/DR terminals reaching the bed nucleus of the stria terminalis (Xu et al., 2021) whereas an in-vitro study demonstrated that D2 autoreceptors regulate DA release in the CeA (Bull et al., 1991). Thus, functional evidence (Bull et al., 1991; Xu et al., 2021) together with histological results shown in this work and in Lein et al. (2007) indicate that DA release in the CeA is regulated by presynaptic D2 autoreceptors. Consequently, pharmacological activation or blockade of D2Rs present in the CeL are likely to alter DA release and affect the activity of CeA neurons expressing postsynaptic DA receptors.

In agreement with a role of D2Rs of the CeA in risk avoidance, our pharmacological results show D2R-mediated activation of CeL PKC $8+$ cells (Fig. 2), a group of neurons that has been shown to elicit anxiolytic-like effects in approach/avoidance conflict tests (Cai et al., 2014; Griessner et al., 2018). Considering that D2Rs are generally Gi/o-coupled receptors that decrease neuronal excitability (Innis and Aghajanian, 1987; Lacey et al., 1987; Uchida et al., 2000), the excitatory effect on PKC $\delta+$ neurons is likely due to polysynaptic transmission, a mechanism that needs to be further clarified in future studies. Because DA agonists were applied systemically in this study, we cannot rule out the possibility that the D2R-mediated activation of CeL PKC $8+$ cells was indirectly driven by stimulation of D2Rs located in other brain areas. Although specific subpopulations of PKC $\delta+$ neurons drive defensive behaviors (Kim et al., 2018; Cui et al., 2017), 
the PKC $\delta+$ neurons activated by quinpirole and cocaine most likely reduce anxiety-like behaviors, as c-FOS expression in the CeA elicited by cocaine or amphetamine can be prevented by exposure to stressful environments (Day et al., 2008; Day et al., 2005; Day et al., 2001), suggesting that indirect DA agonists and potential threats drive opposite effects in CeA microcircuits. Our demonstration that partial ablation of D2Rs from the CeA increased avoidance in exploratory tasks (Fig. 4) without impairing locomotor activity (Fig. 5), together with the finding that D2Rs activate PKC + neurons in the CeL (Fig. 2) suggest that amygdalar D2Rs are potential therapeutic targets for anxiolytic compounds. Interestingly, the D2/D3 agonist ropinirole has shown anxiolytic effects together with motor improvements in Parkinson's disease patients (Rogers et al., 2000; Rektorova et al., 2008; Mavrikaki et al., 2014). In addition, it has been recently shown that $\operatorname{CeL~PKC~} \delta+$ neurons are necessary and sufficient for the anxiolytic effect of benzodiazepines (Griessner et al., 2018).

In summary, here we demonstrate that removing D2Rs in the CeA increases anxiety-like behaviors, as evidenced by reduced exploration of riskier environments. This result is consistent with the work of De Bundel et al., 2017 in which blocking D2Rs in the CeA after a fear conditioning test leads to fear generalization, a clinical marker of anxiety disorders (De Bundel et al., 2016). In contrast, D1R stimulation in the CeA facilitated fear learning (Guarraci et al., 1999b; Groessl et al., 2018) and expression (Guarraci et al., 1999b), without affecting anxietylike behaviors (Groessl et al., 2018). Thus, we hypothesize that DA in the CeA reduces anxietylike behaviors via D2Rs and enhances fear learning and memory via D1R. A similar mechanism has been proposed for DA acting in the striatum, where DA regulates behavioral selection by enhancing the contrast between stronger and weaker inputs reaching striatal neurons (for a review see (Nicola et al., 2004)). We propose that in the CeA, DA strengthens the value of 
aversive stimuli via D1Rs (Guarraci et al., 1999b; Groessl et al., 2018), and attenuates signals from low risk or neutral stimuli via a D2R-based mechanism, as we found here and in agreement with a previous report (De Bundel et al., 2016). Further studies will be necessary to address the participation of other DAergic receptors in amygdalar circuits mediating responses to fearful, dangerous and high risk situations.

\section{References}

Bäckman CM, Malik N, Zhang Y, Shan L, Grinberg A, Hoffer BJ, Westphal H, Tomac AC (2006) Characterization of a mouse strain expressing Cre recombinase from the $3^{\prime}$ untranslated region of the dopamine transporter locus. genesis 44:383-390.

Bello EP, Mateo Y, Gelman DM, Noain D, Shin JH, Low MJ, Alvarez VA, Lovinger DM, Rubinstein M (2011) Cocaine supersensitivity and enhanced motivation for reward in mice lacking dopamine D2 autoreceptors. Nat Neurosci 14:1033-1038.

Bull DR, Bakhtiar R, Sheehan MJ (1991) Characterization of dopamine autoreceptors in the amygdala: A fast cyclic voltammetric study in vitro. Neurosci Lett 134:41-44.

Cai H, Haubensak W, Anthony TE, Anderson DJ (2014) Central amygdala PKC- $\delta+$ neurons mediate the influence of multiple anorexigenic signals. Nat Neurosci 17:1-11.

Ciocchi S, Herry C, Grenier F, Wolff SBE, Letzkus JJ, Vlachos I, Ehrlich I, Sprengel R, Deisseroth K, Stadler MB, Müller C, Lüthi A (2010) Encoding of conditioned fear in central amygdala inhibitory circuits. Nature 468:277-282.

Cui Y, Lv G, Jin S, Peng J, Yuan J, He X, Gong H, Xu F, Xu T, Li H (2017) A Central AmygdalaSubstantia Innominata Neural Circuitry Encodes Aversive Reinforcement Signals. Cell Rep 21:1770-1782.

Day HEW, Badiani A, Uslaner JM, Oates MM, Vittoz NM, Robinson TE, Watson SJ, Akil H (2001) Environmental novelty differentially affects c-fos mRNA expression induced by amphetamine or cocaine in subregions of the bed nucleus of the stria terminalis and amygdala. J Neurosci 21:732-740. 
Day HEW, Nebel S, Sasse S, Campeau S (2005) Inhibition of the central extended amygdala by loud noise and restraint stress. Eur J Neurosci 21:441-454.

Day HEW, Kryskow EM, Nyhuis TJ, Herlihy L, Campeau S (2008) Conditioned fear inhibits c-fos mRNA expression in the central extended amygdala. Brain Res 1229:137-146.

De Bundel D, Zussy C, Espallergues J, Gerfen CR, Girault J-A, Valjent E (2016) Dopamine D2 receptors gate generalization of conditioned threat responses through $\mathrm{mTORC1}$ signaling in the extended amygdala. Mol Psychiatry 21:1545-1553

De la Mora MP, Gallegos-Cari A, Crespo-Ramirez M, Marcellino D, Hansson AC, Fuxe K (2012) Distribution of dopamine D 2-like receptors in the rat amygdala and their role in the modulation of unconditioned fear and anxiety. Neuroscience 201:252-266

Ehrlich I, Humeau Y, Grenier F, Ciocchi S, Herry C, Lüthi A (2009) Amygdala Inhibitory Circuits and the Control of Fear Memory. Neuron 62:757-771.

Frank MJ, Hutchison K (2009) Genetic contributions to avoidance-based decisions: striatal D2 receptor polymorphisms. Neuroscience 164:131-140.

Gong S, Zheng C, Doughty ML, Losos K, Didkovsky N, Schambra UB, Nowak NJ, Joyner A, Leblanc G, Hatten ME, Heintz N (2003) A gene expression atlas of the central nervous system based on bacterial artificial chromosomes. Nature 425:917-925.

Griessner J, Pasieka M, Böhm V, Grössl F, Kaczanowska J, Pliota P, Kargl D, Werner B, Kaouane N, Strobelt S, Kreitz S, Hess A, Haubensak W (2018) Central amygdala circuit dynamics underlying the benzodiazepine anxiolytic effect. Mol Psychiatry Available at:

Groessl F, Munsch T, Meis S, Griessner J, Kaczanowska J, Pliota P, Kargl D, Badurek S, Kraitsy K, Rassoulpour A, Zuber J, Lessmann V, Haubensak W (2018a) Dorsal tegmental dopamine neurons gate associative learning of fear. Nat Neurosci 21:952-962

Guarraci F, Frohardt RJ, Young SL, Kapp BS (1999) A functional role for dopamine transmission in the amygdala during conditioned fear. Ann N Y Acad Sci 877:732-736.

Guarraci F, Frohardt RJ, Falls W a, Kapp BS (2000) The effects of intra-amygdaloid infusions of a D2 dopamine receptor antagonist on Pavlovian fear conditioning. Behav Neurosci 114:647-651. 
Gurevich E V, Ph D, Joyce JN, Ph D (1999) Distribution of Dopamine D 3 Receptor Expressing Neurons in the Human Forebrain : Comparison with D 2 Receptor Expressing Neurons.

Hasue RH, Shammah-Lagnado SJ (2002) Origin of the dopaminergic innervation of the central extended amygdala and accumbens shell: A combined retrograde tracing and immunohistochemical study in the rat. J Comp Neurol 454:15-33.

Haubensak W, Kunwar PS, Cai H, Ciocchi S, Wall NR, Ponnusamy R, Biag J, Dong H-W, Deisseroth K, Callaway EM, Fanselow MS, Lüthi A, Anderson DJ (2010) Genetic dissection of an amygdala microcircuit that gates conditioned fear. Nature 468:270-276.

Innis RB, Aghajanian GK (1987) Pertussis toxin blocks autoreceptor-mediated inhibition of dopaminergic neurons in rat substantia nigra. Brain Res 411:139-143

Janak PH, Tye KM (2015) From circuits to behaviour in the amygdala. Nature 517:284-292.

Joe K, Kim D, Lae B, Yoon S, Lee H, Kim T, Cheon Y, Gwon D, Cho S, Won H, Namgung S, Doo H (2008) Genetic association of DRD2 polymorphisms with anxiety scores among alcoholdependent patients. 371:591-595.

Kim B, Yoon S, Nakajima R, Lee HJ, Lim HJ, Lee YK, Choi JS, Yoon BJ, Augustine GJ, Baik JH (2018) Dopamine D2 receptor-mediated circuit from the central amygdala to the bed nucleus of the stria terminalis regulates impulsive behavior. Proc Natl Acad Sci U S A 115:E10730E10739.

Kim J, Zhang X, Muralidhar S, LeBlanc SA, Tonegawa S (2017) Basolateral to Central Amygdala Neural Circuits for Appetitive Behaviors. Neuron 93:1464-1479.e5.

Koob GF (2008) A Role for Brain Stress Systems in Addiction. Neuron 59:11-34

Lacey MG, Mercuri NB, North RA (1987) Dopamine acts on D2 receptors to increase potassium conductance in neurones of the rat substantia nigra zona compacta. J Physiol 392:397-416

Lawford BR, D M, Young R, D MDP, Noble EP, Ph DMD, Kann B, D M, Ritchie T, Ph D (2006) The D 2 dopamine receptor ( DRD2) gene is associated with co-morbid depression, anxiety and social dysfunction in untreated veterans with post-traumatic stress disorder. 21:180185. 
Lein ES et al. (2007) Genome-wide atlas of gene expression in the adult mouse brain. Nature 445:168-176.

Li C, Sugam JA, Lowery-Gionta EG, McElligott ZA, McCall NM, Lopez AJ, McKlveen JM, Pleil KE, Kash TL (2016) Mu Opioid Receptor Modulation of Dopamine Neurons in the Periaqueductal Gray/Dorsal Raphe: A Role in Regulation of Pain. Neuropsychopharmacology 41:2122-2132

Madisen L, Zwingman TA, Sunkin SM, Oh SW, Hatim A, Gu H, Ng LL, Palmiter RD, Hawrylycz MJ, Allan R, Lein ES, Zeng H (2010) A robust and high-throughput Cre Repooting and characterization. Nat Neurosci 13:133-140.

Mavrikaki M, Schintu N, Nomikos GG, Panagis G, Svenningsson P (2014) Ropinirole regulates emotionality and neuronal activity markers in the limbic forebrain. Int J Neuropsychopharmacol 17:1981-1993.

McCullough KM, Morrison FG, Hartmann J, Carlezon WA, Ressler KJ (2018a) Quantified coexpression analysis of central amygdala subpopulations. eNeuro 5:ENEURO.001018.2018.

McCullough KM, Daskalakis NP, Gafford G, Morrison FG, Ressler KJ (2018b) Cell-type-specific interrogation of CeA Drd2 neurons to identify targets for pharmacological modulation of fear extinction. Transl Psychiatry 8:164.

McDonald AJ (1982) Cytoarchitecture of the central amygdaloid nucleus of the rat. J Comp Neurol 208:401-418.

Nicola SM, Hopf FW, Hjelmstad GO (2004) Contrast enhancement: A physiological effect of striatal dopamine? Cell Tissue Res 318:93-106.

Paxinos G, Franklin K (2008) The Mouse Brain in Stereotaxic Coordinates, Compact.

Rektorova I, Balaz M, Svatova J, Zarubova K, Honig I, Dostal V, Sedlackova S, Nestrasil I, Mastik J, Bares M, Veliskova J, Dusek L (2008) Effects of Ropinirole on Nonmotor Symptoms of Parkinson Disease. Clin Neuropharmacol 31:261-266.

Rogers DC, Costall B, Domeney AM, Gerrard PA, Greener M, Kelly ME, Hagan JJ, Hunter AJ 
(2000) Anxiolytic profile of ropinirole in the rat, mouse and common marmoset. Psychopharmacology (Berl) 151:91-97.

Rueden CT, Schindelin J, Hiner MC, DeZonia BE, Walter AE, Arena ET, Eliceiri KW (2017) ImageJ2: ImageJ for the next generation of scientific image data. BMC Bioinformatics 18:126.

Schindelin J, Arganda-Carreras I, Frise E, Kaynig V, Longair M, Pietzsch T, Preibisch S, Rueden C, Saalfeld S, Schmid B, Tinevez JY, White DJ, Hartenstein V, Eliceiri K, Tomancak P, Cardona A (2012) Fiji: An open-source platform for biological-image analysis. Nat Methods 9:676682.

Schneier FR, Liebowitz MR, Abi-dargham A, Zea-ponce Y, Ph D, Lin S, Ph D, Laruelle M (2000) Low Dopamine D 2 Receptor Binding Potential in Social Phobia. :457-459.

Scibilia RJ, Lachowicz JE, Kilts CD (1992) Topographic nonoverlapping distribution of D1 and D2 dopamine receptors in the amygdaloid nuclear complex of the rat brain. Synapse 11:146154.

Tolu S, Avale ME, Nakatani H, Pons S, Parnaudeau S, Tronche F, Vogt A, Monyer H, Vogel R, de Chaumont F, Olivo-Marin J-C, Changeux J-P, Maskos U (2010) A versatile system for the neuronal subtype specific expression of lentiviral vectors. FASEB J 24:723-730.

Tye KM, Prakash R, Kim S-Y, Fenno LE, Grosenick L, Zarabi H, Thompson KR, Gradinaru V, Ramakrishnan C, Deisseroth K (2011) Amygdala circuitry mediating reversible and bidirectional control of anxiety. Nature 471:358-362.

Uchida S, Akaike N, Nabekura J (2000) Dopamine activates inward rectifier K+ channel in acutely dissociated rat substantia nigra neurones. Neuropharmacology 39:191-201.

Xiang L, Szebeni K, Szebeni A, Klimek V, Stockmeier CA, Karolewicz B, Kalbfleisch J, Ordway GA (2008) Dopamine receptor gene expression in human amygdaloid nuclei: Elevated D4 receptor mRNA in major depression. Brain Res 1207:214-224

Yu W, Pati D, Pina MM, Schmidt KT, Boyt KM, Hunker AC, Zweifel LS, McElligott ZA, Kash TL (2021) Periaqueductal gray/dorsal raphe dopamine neurons contribute to sex differences in pain-related behaviors. Neuron 109:1365-1380 
D2Rs in the CeA regulate risk avoidance - Casey et al., 2021

599

600

601

602

603

604

605

606

607

608

609

610

611

612

613

614

\section{Figure Legends}

Figure 1. Post- and pre-synaptic distribution of D2R-expressing neurons. A) Representative confocal microscopy of coronal sections at two anteroposterior levels of the CeA of a Drd2EGFP mouse. Magnifications of boxed areas are shown in the left bottom corners. B) Representative histology of D2R-expressing neurons (green, left) in CeA coronal sections of Drd2-EGFP.Dat ${ }^{+/ / R E S-C r e}$.Ai14 triple transgenic mice. DAergic fibers (reported by Cre-induced tdTomato, in red) and their overlap with D2R-expressing neurons is shown at the center and right, respectively. C-D) Analysis of Drd2 expression in DAergic neurons of the PAG/DR. C) Representative confocal microscopy of TH immunofluorescence on a PAG/DR coronal section of a Drd2-EGFP mouse. Magnifications of boxed areas are shown. D) Percentage of D2R+ and D2R- neurons from total TH+ neurons in the VPAG/DR (mean $\pm S E M, n=3$ mice). CeL, central nucleus of the amygdala, lateral part; CeM, central nucleus of the amygdala, medial part. Scale bars: $200 \mu \mathrm{m}$. 
615

616

617

618

619

620

621

622

623

624

625

626

627

628

629

630

631

632

633

Figure 2. D2R stimulation activates CeA PKC $\delta$ neurons. A) Representative histology of PKC $\delta$ (green, top) and c-FOS (red, center) double immunofluorescence in coronal sections of the CeA of WT mice receiving vehicle, cocaine $(20 \mathrm{mg} / \mathrm{kg}$, i.p.) or quinpirole $(1 \mathrm{mg} / \mathrm{kg}$, i.p.). Insets are magnifications of the boxed areas. B) Quantification of c-FOS activation induced by cocaine; lines connect data from the same mouse. Two ways generalized linear mixed model with Negative Binomial family (link: log); likelihood-ratio test: Type of neuron, $x^{2}(1)=66.1, p<0.0001$; Drug, $x^{2}(1)=15.4, p<0.0001$; Drug*Type of neuron, $x^{2}(1)=3.5, p=0.06$; vehicle, $n=9$; cocaine, $n=$ 7; post hock Tuckey test shown. C) Quantification of c-FOS activation induced by quinpirole; lines connect data from the same mouse. Two ways generalized linear mixed model with Poisson family (link: log); likelihood-ratio test: Drug*Type of neuron, $x^{2}(1)=9.3, p=0.03$; vehicle, $\mathrm{n}=4$; quinpirole, $\mathrm{n}=4$; post hock Tuckey test shown. D) Representative double immunofluorescence for c-FOS (cyan) and TH (red) in the CeA and (E) quantification of c-FOS expression in the CeA induced by saline (Veh) or quinpirole (Quin) (1 $\mathrm{mg} / \mathrm{kg}$, i.p.) given to wildtype (wt) or Drd2KO (KO) mice. Two ways generalized linear mixed model with Negative Binomial family (link: log); likelihood-ratio test: Drug*Genotype, $x^{2}(1)<8.1, p<0.01$; post hoc Tuckey test shown. Veh: WT, $n=5 ; K O, n=3$; Quin: WT, $n=5 ; K O, n=3$. CeL, CeA, lateral part; CeM, CeA, medial part. Scale bars: $100 \mu$ m. ${ }^{* * *}$ p $<0.001,{ }^{* *} p<0.01$, n.s. $p>0.05$. 
634

635

636

637

638

639

640

641

642

643

644

645

646

647

648

Figure 3. Strategy for selective genetic ablation of D2Rs in the CeA. A) Schematic of the lentiviral vectors used to express Cre driven by the GAD67 promoter and EGFP driven by the ubiquitin promoter. B) Schematic of lentiviral vectors bilateral injections. C) Strategy for generating CeADrd2KO and control mice. D) Experimental timeline. OF, exploratory activity in an open field; EPM, elevated plus maze; DLBT, dark/light box test; FC, fear conditioning. Each vertical bar indicates one day. E) Representative histology of a coronal section showing coinjections of LV:GAD-Cre and LV:Ub-EGFP into the CeA. F) LV:GAD-Cre-induced recombination in $\operatorname{Drd} 2^{\text {loxp/loxP }}$ mice was verified by PCR with primers detecting deleted $\left(\operatorname{Drd} 2^{-}\right)$, floxed $\left(\operatorname{Drd} 2^{\text {loxP }}\right)$ and wild-type $\left(\mathrm{Drd}^{+}\right)$alleles from biopsies containing the CeA or thalamus -as negative controlof CeADrd2KO $(n=4)$ and control $(n=4)$ mice. Result of a mouse per group are shown, followed by a negative control (water) and 2 positive controls. G) Representative histology of a coronal brain section of a Drd2-EGFP.Ai14 double transgenic mouse receiving a stereotaxic injection of LV:GAD-Cre into the CeA. D2R+ (green), Cre-induced tomato (red). 
Figure 4. D2R ablation from the CeA increases avoidance in exploratory tasks. The result of a MANOVA including every measure is shown at the center, right. A) Dark/light box. Top: time spent in the lit chamber. Student's t test, $t(15)=3.4 ; p=0.004$. Middle: latency to first entry into lit chamber in a dark/light box test. Student's $t$ test; $t(15)=-2.3 ; p=0.034$. Bottom: number of entries into the lit chamber in a dark/light box test. Generalized linear model with Poisson family (link: log); Wald test, $z=-1.7, p=0.092$. B) Elevated plus maze. Top: Percentage of time on open arms. Only in this measure, the cohort of mice had a significant effect. Therefore, the percentage of time on open arms was analyzed in 2 different ways (see the "Elevated plus maze" section in Materials and Methods). Top-left: Percentage of time in open arms, 2 way (group $\mathrm{x}$ cohort) ANOVA with variance modeling ("Varldent" function, applied to Cohort factor), Group, $F(1,13)=8.9, p=0.011$; Cohort, $F(1,13)=19.9, p<0.001$; Group*Cohort, $F(1,13)=0.16$, $p=0.69$. Top-right: Percentage of time in open arms normalized to the cohort average. Student's t Test; $\mathrm{t}(15)=2.1 ; \mathrm{p}=0.049)$. Bottom: Percentage of entries to open arms over total entries (open+closed). Since statistical differences between cohorts were not detected, normalization to cohort averages was not performed. Bottom-left: Percentage of entries to open arms over entries to open and closed arms in an elevated plus maze, with data separated according to the cohort. Two-way Generalized linear mixed model with Quasi-binomial family (link: logit); Wald test; Group, $\mathrm{t}=-0.31, \mathrm{p}=0.76$; Cohort, $\mathrm{t}=1.86, \mathrm{p}=0.09$; Group*Cohort, $\mathrm{t}=0.1, \mathrm{p}$ 0.92. Bottom-right) Percentage of entries to open arms, with data of both cohorts pulled. Generalized linear mixed model with Quasi-binomial family (link: logit); Wald test, $t=-0.37, p=$ $0.72 \mathrm{C}$ ) Open field. Time in center of the arena during the first $5 \mathrm{~min}$ of exposure. Student's $\mathrm{t}$ test, $\mathrm{t}(15)=0.35, \mathrm{p}=0.73$. CeADrd2KO, $\mathrm{n}=9 ; \mathrm{Ctrl}, \mathrm{n}=8$ in all experiments. ${ }^{* *} \mathrm{p}<0.01,{ }^{*} \mathrm{p}<0.05$, n.s. $p>0.05$.

Figure 5. D2R ablation from the CeA does not affect locomotion. Daily distance travelled by CeADrd2KO and control mice during 30 min sessions of open field exploration; 2 way ANOVA with repeated measures; Group, $F(1,45)=0.001, p>0.1$; Days, $F(2,45)=76.3, p<0.001$; Group*Days, $F(2,45)=2, p>0.1$. CeADrd2KO, $n=9$ and Ctrl, $n=8$. n.s., $p>0.05$. 
677 Figure 6. LV:GAD-Cre injections into the CeA of $\mathrm{Drd2}^{+/+}$mice does not alter behaviors in exploratory tasks. A) Experimental design with viral injections. B) Experimental timeline. OF, exploratory activity in an open field; EPM, elevated plus maze; DLBT, dark/light ox test. Each vertical bar indicates one day. C-E) Avoidance behavior in exploratory tasks. The result of a MANOVA including every measure is shown in the center. C) Dark/light box. Top: time in the lit chamber. Student's t test, $\mathrm{t}(12)=1.3 ; \mathrm{p}=0.22$. Middle: latency to first entry to light chamber; Student's t test; $\mathrm{t}(12)=1.1, \mathrm{p}=0.29$. Bottom: number of entries to light chamber; Generalized linear model with quasi-Poisson family (link: $\log$ ); Wald test, $z=1.51, p=0.16$. D) Elevated plus maze. Top: percentage of time on the open arms over the time on open and closed arms; Student's t test; $\mathrm{t}(12)=0.21 ; \mathrm{p}=0.83$. Bottom: Percentage of entries to open arms over total. Generalized linear mixed model with Quasi-binomial family (link: logit); Wald test, $z=-0.49, p=$ 0.64. E) Open field. Time in center of the arena during the first $5 \mathrm{~min}$ of exposure; Student's $\mathrm{t}$ test, $\mathrm{t}(12)=1.1, \mathrm{p}=0.29$. LV:GAD-Cre, $\mathrm{n}=7$; LV:Ub-EGFP, $\mathrm{n}=7$ in all the experiments. $* * \mathrm{p}<0.01, *$ $p<0.05$, n.s. $p>0.05$.

Figure 7. Mice lacking $D 2 R$ in the CeA express unaltered fear-conditioning memory. A) Contextual fear conditioning training protocol. B) Percentage of freezing during the first 2 min of chamber habituation during the training (Pre-test, Generalized linear model with quasibinomial family (link: log); Wald test, $z=1.23, p=0.23$ ). C) Percentage of freezing after each foot shock (Training session, Generalized linear mixed model with quasi-binomial family (link: log); LRT test; Group*Shock, $X^{2}(1)=2.8, p=0.24$; Group, $X^{2}(1)=0.2, p=0.65$; Shock, $X^{2}(1)=21.7$, $\mathrm{p}<0.001)$. D) Percentage of freezing during re-exposition to the conditioning chamber, $24 \mathrm{~h}$ after the training (testing session, Generalized linear model with quasi-binomial family (link: log); Wald test, $z=0.15, p=0.88$ ). Result of MANOVA including all variables is shown. CeADrd2KO, $n=9$ and Ctrl, $n=8$. n.s., $p>0.05$. 
A

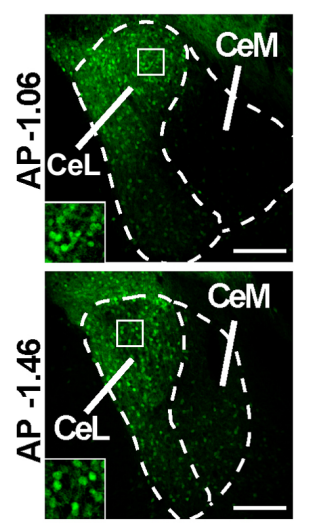

B

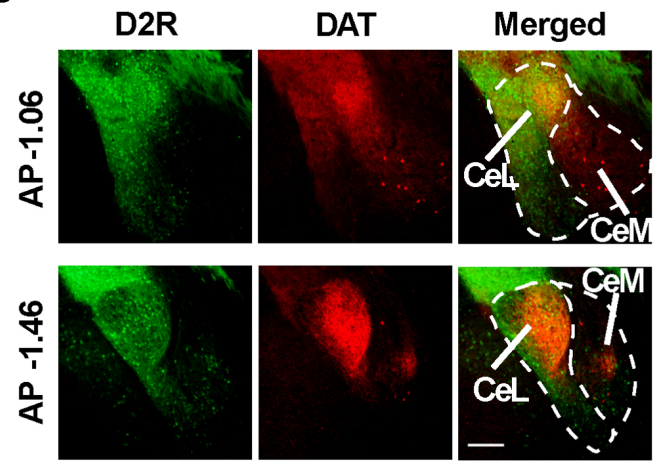

C
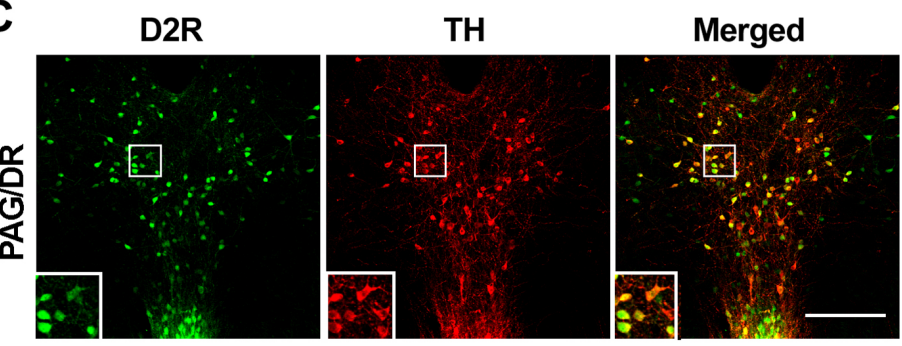

D

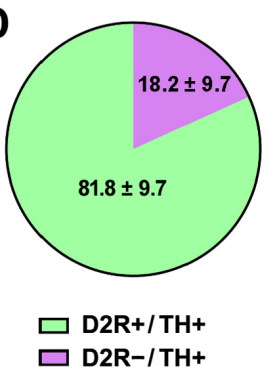

Fig. 1 

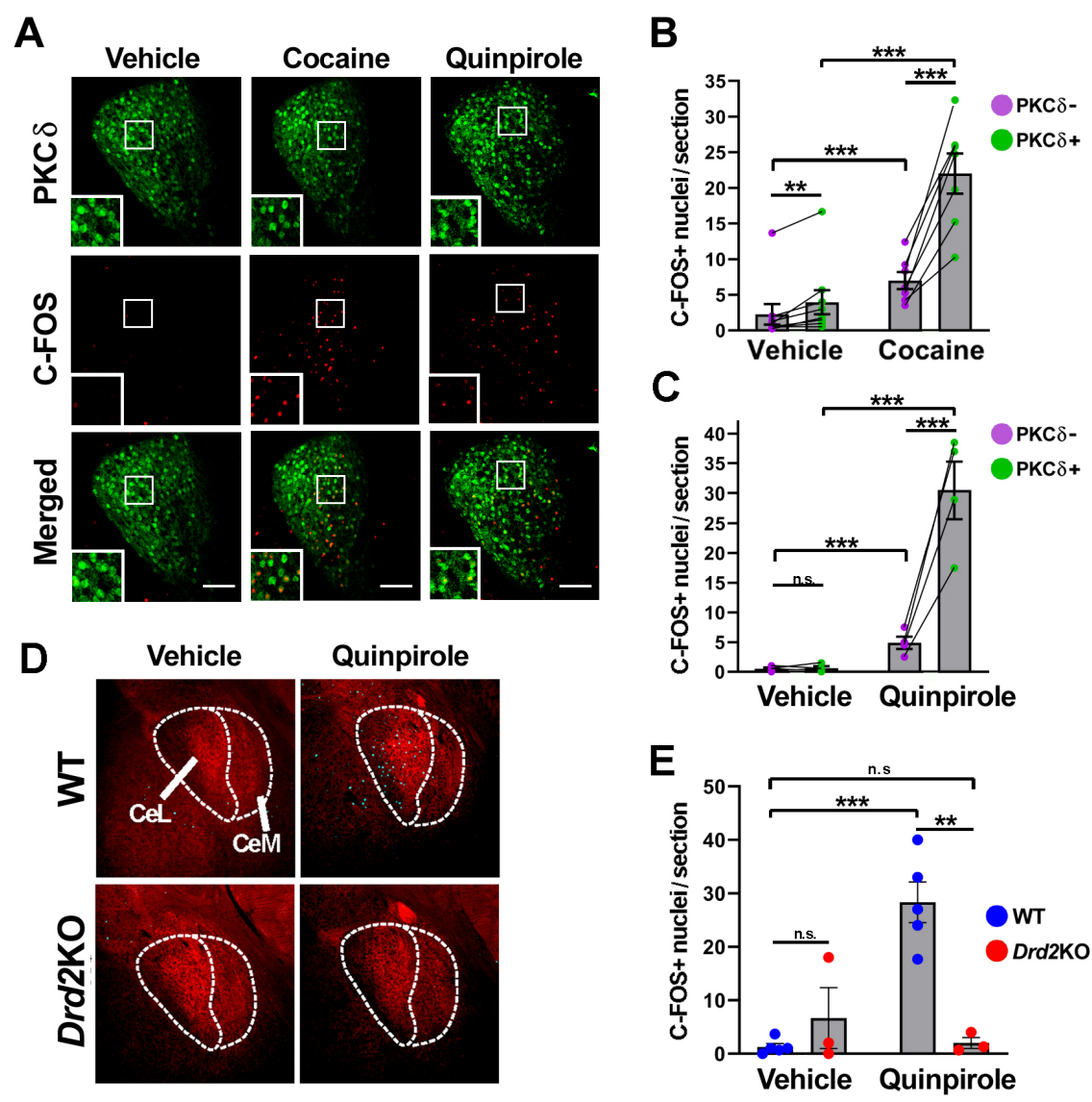

Fig. 2 
A LV:GAD-Cre

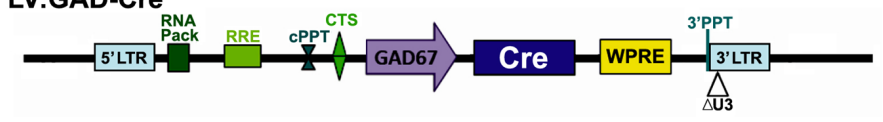

LV:Ub-EGFP

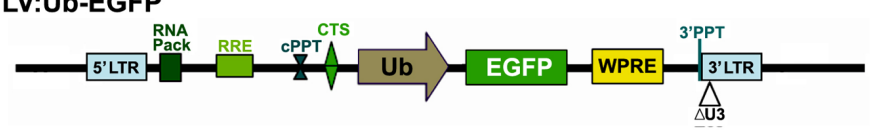

C

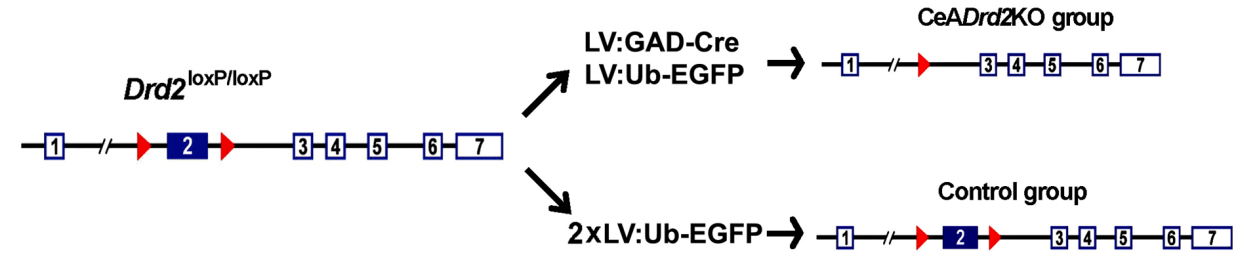

D

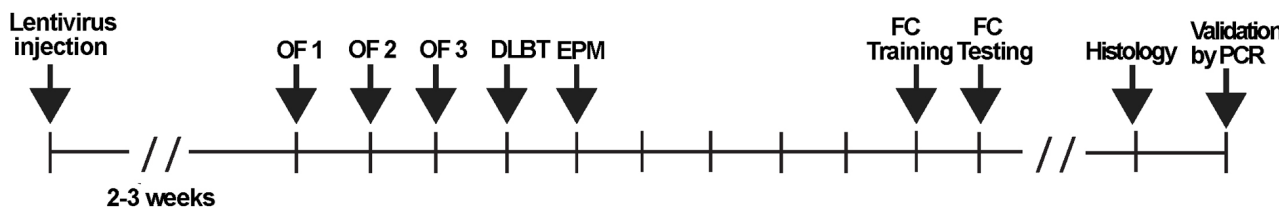

E

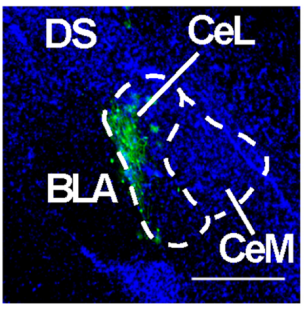

$\mathbf{F}$

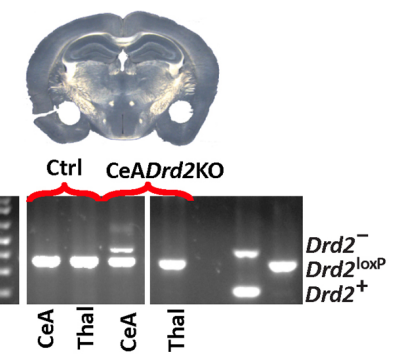

B

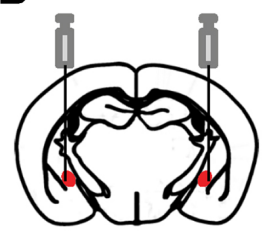

G Ai14.D2R-EGFP

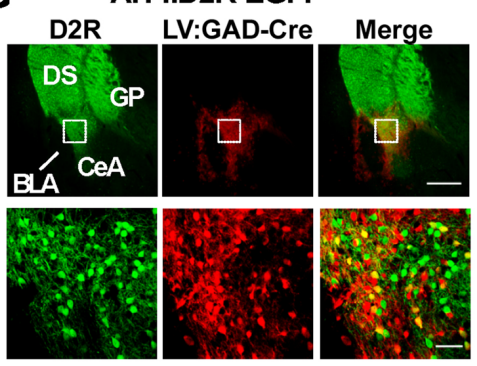

Fig. 3 


\section{A Dark/light box}
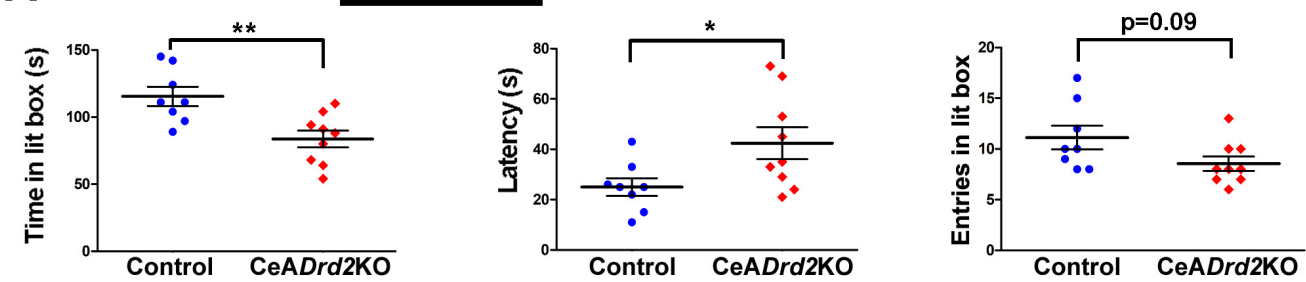

\section{B Elevated plus maze}

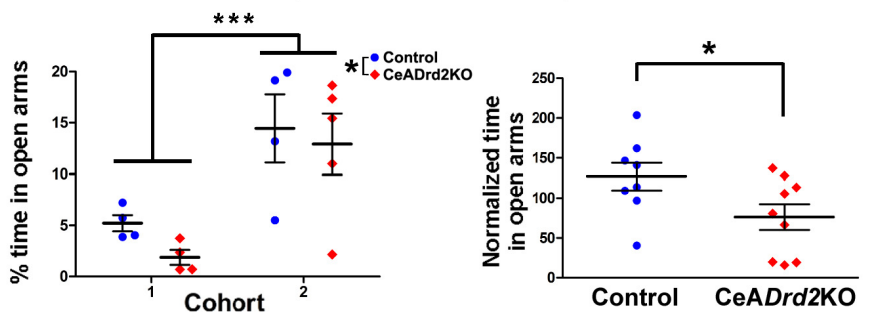

MANOVA: $p=0.03$
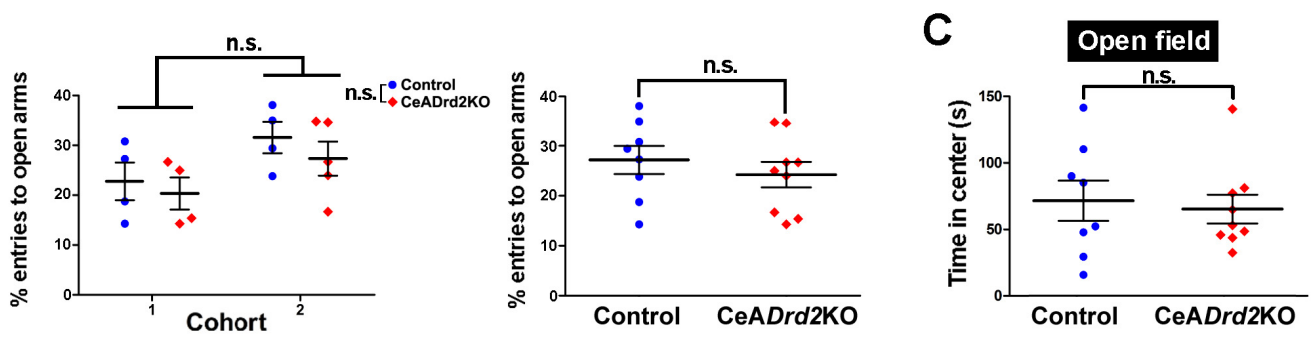

Fig. 4 


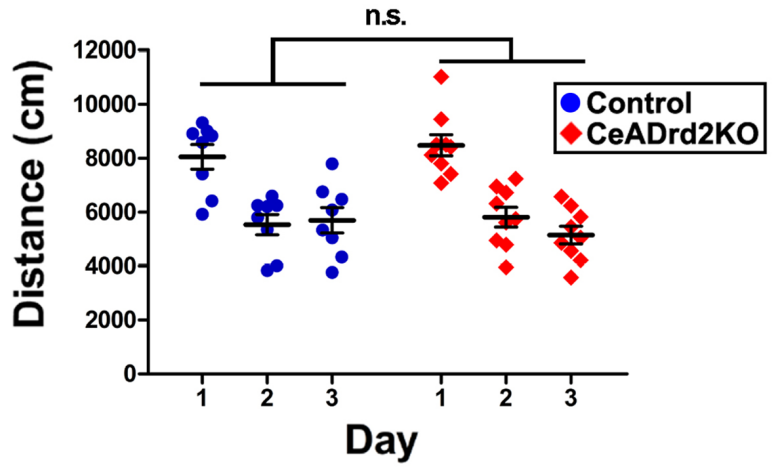

Fig. 5 


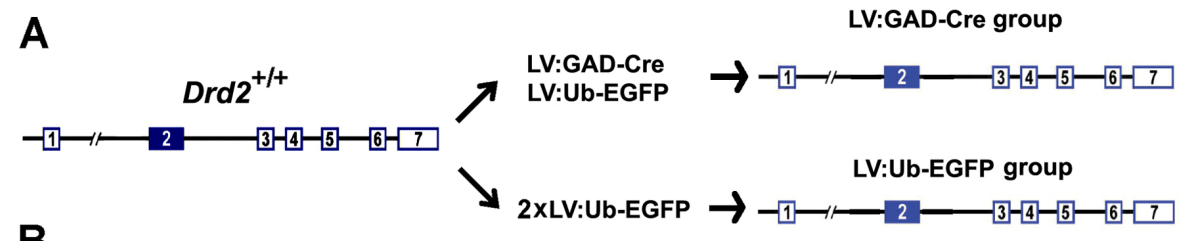

B

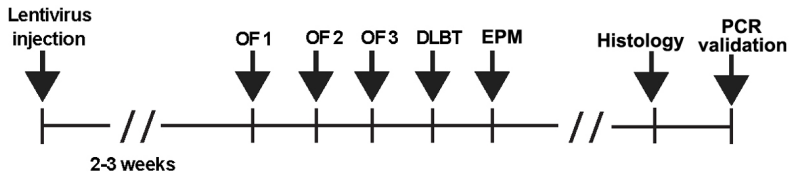

C Dark/light box
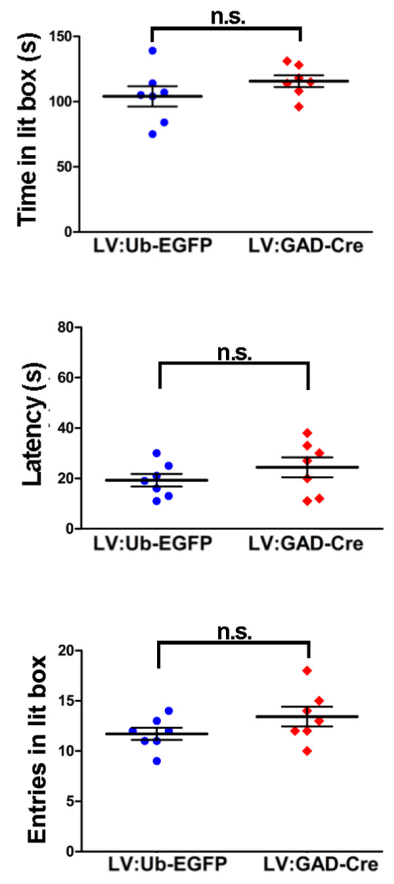

D Elevated plus maze

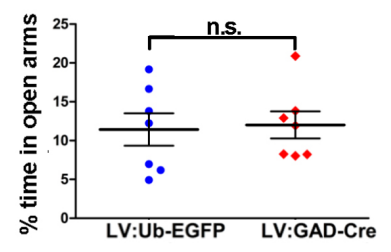

MANOVA: $p=0.48$

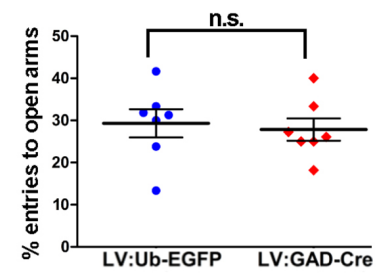

E

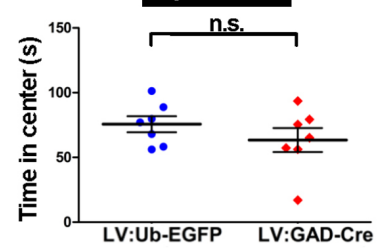

Fig. 6 
Casey et al., 2021
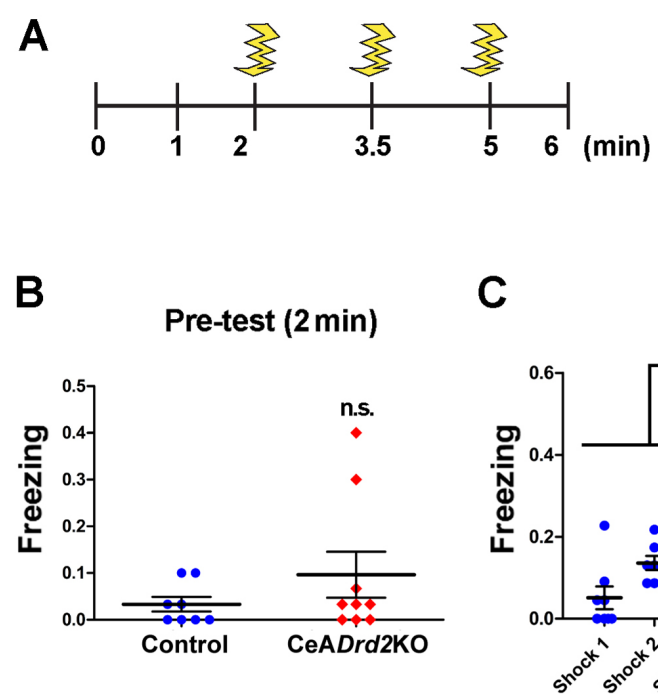

C

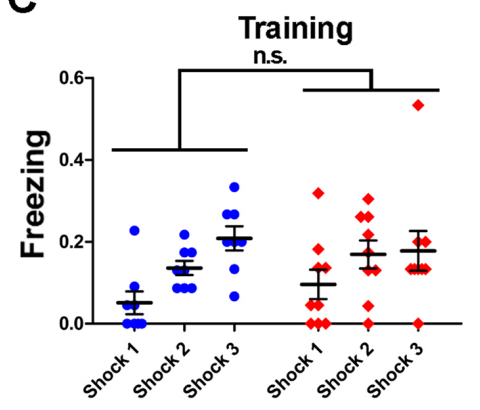

D

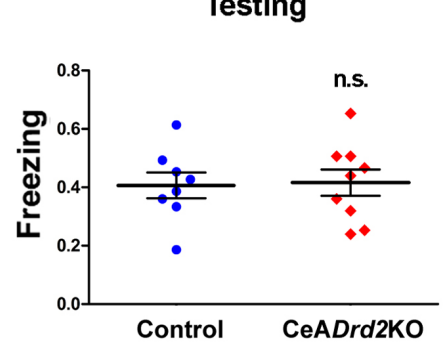

MANOVA: $p=0.67$

Fig. 7 